\title{
Interdisciplinarity and innovation dynamics. On convergence of research, technology, economy, and society
}

\author{
Klaus Mainzer
}

Published online: 29 April 2011

(C) Springer-Verlag 2011

\begin{abstract}
In the age of globalization, economic growth and the welfare of nations decisively depend on basic innovations. Therefore, education and knowledge is an important advantage of competition in highly developed countries with high standards of salaries, but raw material shortage. In the twenty-first century, innovations will arise from problem-oriented research, crossing over traditional faculties and disciplines. Therefore, we need platforms of interdisciplinary dialogue to choose transdisciplinary problems (e.g., environment, energy, information, health, welfare) and to cluster new portfolios of technologies. The clusters of research during the excellence initiative at German universities are examples of converging sciences. The integration of natural and engineering sciences as well as medicine can only be realized if the research training programs (e.g., graduate schools) generate a considerable added value in terms of multidisciplinary experience, international networking, scientific and entrepreneurial know-how, and personality development. The Carl von Linde-Academy is presented as an example of an interdisciplinary center of research and teaching at the Technical University of Munich.
\end{abstract}

Zusammenfassung Im Zeitalter der Globalisierung hängen ökonomisches Wachstum und die Wohlfahrt der Nationen entscheidend von ihrem Innovationspotential ab. Bildung, Wissen und Können sind entscheidende Wettbewerbsvorteile in hoch entwickelten Gesellschaften mit hohen Lohnkosten, aber geringen natürlichen Ressourcen. Im 21. Jahrhundert entstehen Innovationen zunehmend in problemorientierter Forschung, jenseits der traditionellen Grenzen von Fächern und Fakultäten. Daher benötigen wir interdisziplinäre Plattformen, um transdisziplinäre Probleme (z.B. Umwelt, Nachhaltigkeit, Energie, Information, Gesundheit, Wohlfahrt) auszuwählen und in passenden Portfolios von Technologien

K. Mainzer $(\bowtie)$

Lehrstuhl für Philosophie und Wissenschaftstheorie, Direktor der Carl von Linde-Akademie,

Technische Universität München, Arcisstrasse 21, 80333 Munich, Germany

e-mail: mainzer@cvl-a.tum.de 
weiterzuentwickeln. Die Forschungscluster der Exzellenzinitiative an deutschen Universitäten liefern Beispiele für konvergierende Wissenschaft und Technologie. Die Integration von Natur- und Ingenieurwissenschaften ebenso wie der Medizin kann nur realisiert werden, wenn die Trainingsprogramme des wissenschaftlichen Nachwuchses (z.B. Graduiertenschulen) beträchtliche zusätzliche Investitionen für multidisziplinäre Erfahrung, internationale Netzwerke, unternehmerisches Knowhow und Persönlichkeitsentwicklung aufbringen. Die Carl von Linde-Akademie wird als Beispiel eines interdisziplinären Zentrums der Forschung und Lehre an der Technischen Universität München vorgestellt, das sich um die Integration dieser Investitionen kümmert.

Résumé A l'époque de la globalisation, la croissance économique et le bien-être des nations dépendent de manière décisive de leur potentiel d'innovation. L'éducation, la connaissance et les capacités sont des avantages compétitifs décisifs dans des sociétés hautement développées ayant des salaires élevés mais peu de ressources naturelles. Au $21^{\text {ième }}$ siècle des innovations naissent de plus en plus de la recherche axée sur des problèmes, au-delà des frontières traditionnelles des matières et des facultés universitaires. Nous avons de ce fait besoin de plateformes interdisciplinaires pour pouvoir choisir des problèmes transdisciplinaires (par exemple l'environnement, le développement durable, l'énergie, l'information, la santé, l'aide sociale) et les développer dans des portfolios de technologies appropriés. Les groupes de recherche sur les initiatives d'excellence au sein des universités allemandes (Forschungscluster der Exzellenzinitiative an deutschen Universitäten) donnent des exemples de convergences de technologie et de science. L'intégration des sciences naturelles et d'ingénierie ainsi que de la médecine ne peut être réalisée que si les programmes de formation des jeunes scientifiques (par exemple, des écoles d'études avancées) réunissent des investissements considérables supplémentaires dans des expériences multidisciplinaires, des réseaux internationaux, le développement des connaissances et de la personnalité de l'entrepreneuriat. L'Académie Carl von Linde à l'Université Technique de Munich est un exemple d'un centre de recherche et de formation interdisciplinaire qui s'occupe de l'intégration de ces investissements.

\section{Innovation dynamics and globalization}

The first Academy of Europe was founded by the philosopher Plato in 385 B.C near Athens. Many important scholars of antiquity taught at the Academy. Students were educated in the mathematical disciplines of geometry, arithmetic, astronomy, and music as well as logic, physics, metaphysics, and ethics. The Academy was organized as a private cultural association in honor of the Muses. A chairman was responsible to the state of Athens. The buildings, library, and park were initially sponsored by Plato himself, later on by private sponsorship.

In a famous picture of Raffael, the School of Athens was glorified as the paradigm of philosophy and science: The idealist Plato points to heaven as symbol of his doctrine of ideas and cosmology, the realist Aristotle points to the earth as 
application of physics and ethics. In Raffael's painting, Plato and Aristotle are surrounded by scholars of the mathematical sciences on the right and scholars of language, grammar, and rhetoric skills on the left. Obviously, the picture illustrates an early unity of science and educational skills, influencing the development of western universities until modern times.

In the nineteenth century, the humanities and the natural sciences started a successful growth in German universities mainly supported by the two brothers von Humboldt: Wilhelm von Humboldt (1767-1835), a recommended linguistic scholar, reorganized education as Prussian minister and demanded a universal educational unity of teaching and research at universities. Alexander von Humboldt (1769-1859) became the ideal of a universally cultivated natural scientist. His exploring expeditions and publications on, e.g., "Cosmos", became famous all over the world.

In the age of industrialization, the growth of economy needed technical education of engineers. During the French Revolution, technical, administrative, and humanistic education were already proclaimed as ideals of Enlightenment. According to the École Polytechnique (1794) in Paris, the first Technical Universities in German-speaking countries were founded in Prague (1806), Vienna (1815), Karlsruhe (1825), and Munich (1868). The Technical University of Munich (TUM) started with departments of (1) mathematics, physics, economics, and humanities, (2) engineering sciences, (3) architecture, (4) machine building, and (5) technical chemistry.

During this period of pioneers, a new type of inventor, entrepreneur, and university professor, unified in one person, was born: Carl von Linde (1842-1934) was inventor (refrigeration technology), entrepreneur (the Linde company), and professor for theoretical mechanical engineering at the Technical University of Munich. He realized cross-thinking and cross-acting between science and economy with revolutionary research and successful innovations. His Christian education as son of a Protestant reverend inspired his ethics of responsibility and social engagement. His best student Rudolf Diesel (1858-1913) was an ingenious inventor (Diesel engine) and gifted writer on social problems who published a book on "solidarism" (1903) beyond former capitalism and socialism.

Linde and Diesel were examples for several highlights of technical creativity in Europe. The invention dynamics in modern times can be studied by time series with annual numbers of inventions, discoveries, and other cultural achievements of natural sciences and technology. Important basic inventions are characterized by chain reactions of following inventions. From an economic point of view, we distinguish invention and innovation dynamics. Inventions are creative technical novelties according to the demands of patentability. Innovations are inventions, which can be bought and sold as economic products on markets. Time series with annual numbers of basic innovations are correlated with basic inventions. There seems to be a kind of "echo effect", when innovations follow inventions with a certain distance of time.

There is also a correlation between innovation dynamics and business cycles. The Austrian economist Joseph A. Schumpeter (1883-1950) distinguished long-term Kondratieff business cycles (54 years), Juglar cycles (7-11 years), and Kitchin 
cycles (3-5 years) (Schumpeter 1939). Sometimes, there are correlations and superpositions of these curves, which can mathematically be separated by, e.g., Fourier analysis. Basic inventions (e.g., steam engine, automobile) are not continuous and randomly distributed along the time axis, but concentrate in swarm-like clusters at points of instability and initiate long-term Kondratieff business cycles. Beyond Schumpeter's business cycles, we can analyze the nonequilibrium dynamics of markets by modern theory of nonlinear complex systems (Mainzer 2005, 2007).

In former times, education and economy were considered completely separated fields of a society. An exciting idea is the insight that education could influence and depend on invention, innovation, and business dynamics. Actually, there are correlations between business cycles, educational shares, growth of science and technology, and innovation cycles in Europe. The Kondratieff cycles of business are followed by increasing educational shares. The increase in educational shares is correlated to the dynamics of science and technology. But, sometimes, the innovation dynamics has a too long lag to the technical-scientific cycle. For the future of highly developed countries, it is a challenge to correlate educational, business, and innovation dynamics.

In the age of globalization, economic growth and the welfare of nations decisively depend on basic innovations. Therefore, education and knowledge is an advantage of competition in highly developed countries of Europe with high standards of salaries, but raw material shortage (e.g., Germany). The European Union (EU) tries to concentrate educational potentials in order to be successful in the global competition of educational markets. Therefore, Europe is on its way to a European university. This development is called Bologna process. In 1999, the unification of educational standards at European universities was settled in Europe's oldest university city Bologna (Italy): It is Bologna's vision that students should study under the same conditions and with the same academic degrees at all universities of the EU. Further on, the modularization of Bachelor and Master programs should improve the flexibility of studies with respect to changing conditions of offer and demand on the job markets. The structure of Bachelor, Master, and Ph.D. has been introduced in the humanities, sciences, and engineering disciplines. But the Bologna process at universities, at least in Germany, suffers from inflexibility.

\section{Convergence and transdisciplinarity of research}

In recent time, innovations emerge from problem-oriented research overcoming traditional boundaries of disciplines (e.g., material research, energy, environment, health, aging society). If problem-oriented research is beyond former divisions of faculties, it is sometimes called "transdisciplinary". Interdisciplinary dialogues are needed to find transdisciplinary problems and new portfolios of technologies.

Even basic natural sciences like physics, chemistry, and biology converge partially, when they approach common research objects with common scaling of size. Physics is not only the science of the biggest structures in cosmology and 
astronomy or the smallest structures in elementary particle physics. In recent time, material research on nano-sized structures is of enormous industrial interest. In chemistry, the analysis and synthesis of nano-sized macromolecules lead to the new discipline of supramolecular chemistry. Biology has miniaturized from the analysis of organisms to cells and finally functional design of nano-sized biomolecules. Thus, the integrated applications of physical, chemical, and biological principles support the development of new clusters of research and portfolios of technologies.

The Fraunhofer Association recently distinguished four main clusters of research with the abbreviations "nano" for nano and material sciences, "bio" for life sciences and medicine, "info" for information and computer science, and "cogno" for cognition and neuroscience. They all grow together with converging technologies. Contrary to former centuries, the convergence of disciplines and the emergence of new research clusters are not only driven by epistemic interests but by the demand of new products and the competition of global markets.

Nano research was initiated by Richard Feyman's famous statement: “There's plenty of room at the bottom." (Feynman 1959) He referred to the huge variety of possible arrangements of atoms in molecular clusters with nano size, which have not been realized by nature. Under appropriate constraints, atoms can assemble themselves in clusters with different features of materials. Nanotechnologies use this kind of self-organization, in order to generate new materials and artificial organic tissues. Supramolecular chemistry does not only explain the chemical evolution of macromolecules in nature but systematically synthesizes complex molecular clusters by self-organizing chemical reactions for applications in pharmacy and medicine (Mainzer 2008b, 2009). During chemical evolution, nature already generated complex biomolecules like proteins, nucleic acids, lipids, and polysaccharides as building blocks of living cells. A ribosome can be considered a cellular nano machine producing chains of amino acids of a protein as output from the information input of a RNA tape.

Nano and biotechnology are combined in studies of living cells growing together with nano materials in tissue engineering which is, for example, used in plastic surgery. Biohybrid electronic circuits and biological functions are connected to test the interface of living organisms and machines (for example, neurons of rats growing on a silicon chip).

In modern systems biology, mathematics, physics, and computer science grow together with biology, in order to model and to explain the complexity of life (Mainzer 2010). Systems biology maps the molecular, cellular, organic, human, and ecological levels of life in models of complex systems. They are described by nonlinear differential equations representing their complex circular interactions. From a methodological point of view, systems biology is extremely interesting, because computer models and computer simulations (experiments in silico) and laboratory experiments (experiments in vitro and in vivo) are connected in order to generate new knowledge. The increasing complexity of biological data needs the support of machine learning algorithms. For example, the complex network of proteins and their interactions in an Escherichia coli bacterium is reconstructed step by step by the interaction of computational machine learning, data mining, and laboratory experiments. From an interdisciplinary point of view, it is remarkable 
that the clustering structure of these subcellular networks can also be found in neural networks of the central nervous system or information networks of technical electronic systems (e.g., World Wide Web).

Systems biology is an analytical science reconstructing the complex circuits of life with methods of mathematical calculus (differential equations). Synthetic biology is engineering biology aiming at the construction of new biological systems (e.g., bacteria for cleaning polluted water). Biobricks are used as standardized building blocks. In a bottom-up approach, new microorganisms are constructed by nano materials. In a top-down approach, the features of a natural microorganism are reduced to their vital minimum indispensable to life. This kind of basic "chassis" can be extended like a car with any kind of "equipment" for specialized purposes.

After "nano", "info", and "bio", let us consider "cogno". The coordination of the complex cellular and organic interactions in an organism is built upon a kind of self-organizing control. That was made possible by the evolution of nervous systems that also enabled organisms to adapt to changing living conditions and to learn from experiences with their respective environments. The hierarchy of anatomical organizations varies over different scales of magnitude, from molecular dimensions to that of the entire central nervous system (CNS). The research perspectives on these hierarchical levels may concern questions, for example, of how signals are integrated in dendrites, how neurons interact in a network, how networks interact in a system like vision, how systems interact in the CNS, or how the CNS interacts with its environment. Each stratum may be characterized by a dynamical system determining its particular structure, which is caused by complex interactions of subsystems with respect to the particular level of hierarchy.

The neural self-organization on the cellular and subcellular level is determined by the information processing in and between neurons. Chemical transmitters can effect neural information processing with direct and indirect mechanisms of great plasticity. Long-term potentiation (LTP) of synaptic interaction is an extremely interesting topic of brain research. LTP seems to play an essential role for the neural self-organization of cognitive features such as memory and learning. The information is assumed to be stored in the synaptic connections of neural cell assemblies with typical macroscopic patterns.

But while an individual neuron does not see or reason or remember, brains are able to do so. Vision, reasoning, and remembrance are understood as higher-level functions. Scientists who prefer a bottom-up strategy recommend that higher-level functions of the brain can be neither addressed nor understood until each particular property of each neuron and synapse is explored and explained. An important insight of the complex system approach discloses that emergent effects of the whole system are synergetic system effects, which cannot be reduced to the single elements. They are results of nonlinear interactions. Therefore, the whole is more than the (linear) sum of its parts. Thus, from a methodological point of view, a purely bottom-up strategy of exploring the brain functions must fail. On the other hand, the advocates of a purely top-down strategy proclaiming that cognition is completely independent of the nervous system are caught in the old Cartesian dilemma "How does the ghost drive the machine?" 
PET (positron emission tomography) pictures show macroscopic patterns of neurochemical metabolic cell assemblies in different regions of the brain, which are correlated with cognitive abilities and conscious states such as looking, hearing, speaking, or thinking. Pattern formation of neural cell assemblies is even correlated with complex processes of psychic states. Perturbations of metabolic cellular interactions (for example, cocaine) can lead to nonlinear effects initiating complex changes of behavior (for example, addiction by drugs). These correlations of neural cell assemblies and attractors of cognitive and conscious states demonstrate the connection of neurobiology and cognitive psychology in recent research, depending on the standards of measuring instruments and procedures (Freeman 2004).

In order to model the brain and its complex abilities, it is quite adequate to distinguish the following categories. In neuronal-level models, studies are concentrated on the dynamic and adaptive properties of each nerve cell or neuron, in order to describe the neuron as a unit. In network-level models, identical neurons are interconnected to exhibit emergent system functions. In nervous-system-level models, several networks are combined to demonstrate more complex functions of sensory perception, motor functions, stability control, etc. In mental-operation-level models, the basic processes of cognition, thinking, and problem solving are described.

Brains are neural systems, which allow quick adaption to changing situations during lifetime of an organism. Neural networks are complex systems (Mainzer 2008a) of threshold elements with firing and nonfiring states, according to learning strategies (e.g., Hebbian learning). Beside deterministic homogeneous Hopfield networks, there are so-called Boltzmann machines with stochastic network architecture of nondeterministic processor elements and a distributed knowledge representation, which is described mathematically by an energy function. While Hopfield systems use a Hebbian learning strategy, Boltzmann machines favor a backpropagation strategy (Widrow-Hoff rule) with hidden neurons in a manylayered network.

In general, it is the aim of a learning algorithm to diminish the informatictheoretic measure of the discrepancy between the brain's internal model of the world and the real environment via self-organization. The interest in the field of neural networks is mainly inspired by the successful technical applications of statistical mechanics and nonlinear dynamics to solid state physics, spin glass physics, chemical parallel computers, optical parallel computers, or laser systems. Other reasons are the recent development of computing resources and the level of technology, which make a computational treatment of nonlinear systems more and more feasible (Mainzer 2007).

A simple robot with diverse sensors (for example, proximity, light, collision) and motor equipment can generate complex behavior by a self-organizing neural network. In the case of a collision with an obstacle, the synaptic connections between the active nodes for proximity and collision layer are reinforced by Hebbian learning: A behavioral pattern emerges in order to avoid collisions in future (Pfeifer and Scheier 2001). In the human organism, walking is a complex bodily self-organization, largely without central control of brain and consciousness. It is 
driven by the dynamical pattern of a steady periodic motion, the attractor of the motor system.

In the research project "Cognition in Technical Systems" (CoTeSys 2006-2011), which has been supported during the initiative of excellence at the Technical University of Munich, cognitive and life sciences, information processing and mathematical sciences, engineering, and robotics work systematically together to explore cognition for technical systems. Robotic agents cannot be fully programmed for every application. The program learns from experience where to stand when taking a glass out of a cupboard, how to best grab particular kitchen utensils, where to look for particular cutlery, etc. This requires the control system to know the parameters of control routines and to have models for how the parameters change the behavior. The sensor data of a robot's environment, which is the robot's "experience", are stored in a relational database system, the robot's "memory". According to the paradigm of probabilistic robotics (Thrun et al. 2005), the data in the database together with causal structure on domain relations imply a joint probability distribution over relations in the activity domain. This distribution is applied in Marcov logic, which allows inferring the conditional probability of logical (first order) statements. In short, a robot can estimate the environmental situation probabilistically.

A robot can be described at different levels, in which global properties at one level emerge from the interaction of a number of simple elements at lower levels (Bekey 2005). Global properties are emergent in the sense that they result from nothing else but local interactions among the elements. They cannot be predicted or inferred from knowledge of the elements or of the rules by which the elements locally interact, given the high nonlinearity of these interactions.

Simple examples of embodied robotics are reactive robots. They are controlled by simple neural networks, for example, fully connected perceptrons without internal layers and without any kind of internal organization. Nevertheless, these robots can display not only simple behaviors, such as obstacle avoidance, but also behaviors capable of solving complex problems involving perceptual aliasing, sensory ambiguity, and sequential organization of subbehaviors. The question arises how far we can go with reactive sensory-motor coordination (Floreano et al. 1996).

The emergence of cognitive and emotional states is made possible by brain dynamics, which can be modeled by neural networks. In complex dynamical systems, the rules of locally interacting elements (for example, Hebb's rules of synaptic interaction) may be simple and programmed in a computer model. But their nonlinear dynamics can generate complex patterns and system states, which cannot be forecast in the long run without increasing loss of computability and information. Thus, artificial minds could have their own intentionality, cognitive and emotional states, which cannot be forecast and computed similar as is the case with natural minds. Limitations of computability are characteristic features of complex systems.

Robots and computer are no longer isolated machines. Human civilization grows together with global information networks that seem to become the central nervous system of mankind as a kind of superorganism. Actually, the network of the World Wide Web has features of self-organizing routing with information packets reminding us of neural dynamics in brains. Users are overwhelmed by an increasing 
information flood, which cannot be handled by traditional information retrieval. Thus, intelligent information agents help to read, to understand, and to select information (e.g., e-mails) according to the preferences of users. The Internet should no longer be a stupid database with symbol and pictures the meaning of which occurs in the mind of a user only. In order to manage the complexity of data, the net must learn to recognize and understand the meaning of information (Balke and Mainzer 2005). Semantic nets are equipped with extendable background information (ontologies, concepts, relations, maps, facts) and logical rules of conclusion, in order to supplement incomplete knowledge and to draw conclusions autonomously.

In a next step, information networks grow together with public networks of delivery (Mainzer 2010). A smart grid is a form of electricity network utilizing digital technology. A smart grid delivers electricity from suppliers to consumers using two-way digital communications to control appliances at consumers' homes. This saves energy, reduces costs, and increases reliability and transparency. It overlays the ordinary electrical grid with an information system. Smart grids are being promoted by many governments as a way of addressing energy independence, global warming, and emergency resilience issues.

A smart grid is made possible by applying sensing, measurement, and control devices with two-way communications to electricity production, transmission, distribution, and consumption parts of the power grid that communicate information about grid condition to system users, operators, and automated devices, making it possible to dynamically respond to changes in grid condition. A smart grid includes an intelligent monitoring system that keeps track of all electricity flowing in the system. It also has the capability of integrating renewable electricity such as solar and wind. When power is least expensive, the user can allow the smart grid to turn on selected home appliances such as washing machines or factory processes that can run at arbitrary hours. At peak times, it could turn off selected appliances to reduce demand.

The function of an electrical grid is not a single entity but an aggregate of multiple networks and multiple power generation companies with multiple operators employing varying levels of communication and coordination, most of which is manually controlled. Smart grids increase the connectivity, automation, and coordination between these suppliers, consumers, and networks that perform either long distance transmission or local distribution tasks. This paradigm is changing as businesses and homes begin generating more wind and solar electricity, enabling them to sell surplus energy back to their utilities.

Smart grids are only the first steps to a global convergence of technical infrastructures with information networks. A cyber-physical system (CPS) is a system featuring a tight combination of, and coordination between, the system's computational and physical elements. Today, a precursor generation of cyberphysical systems can be found in areas as diverse as aerospace, automotive, chemical processes, civil infrastructure, energy, health care, manufacturing, transportation, entertainment, and consumer appliances. This generation is often referred to as embedded systems. In embedded systems, the emphasis tends to be more on the computational elements and less on an intense link between the computational and physical elements. 
Unlike more traditional embedded systems, a full-fledged CPS is typically designed as a network of interacting elements with physical input and output instead of as standalone devices. The notion is closely tied to concepts of robotics and sensor networks. The expectation is that in the coming years, ongoing advances in science and engineering will improve the link between computational and physical elements, dramatically increasing the adaptability, autonomy, efficiency, functionality, reliability, safety, and usability of cyber-physical systems. The advances will broaden the potential of cyber-physical systems in several dimensions, including intervention (e.g., collision avoidance), precision (e.g., robotic surgery and nanolevel manufacturing), operation in dangerous or inaccessible environments (e.g., search and rescue, firefighting, and deep-sea exploration), coordination (e.g., air traffic control, war fighting), efficiency (e.g., zero-net energy buildings), and augmentation of human capabilities (e.g., health care monitoring and delivery).

\section{Human creativity and key qualifications}

What is the reason of human inventions and innovations? What does human creativity make possible? Which consequences can be concluded for education? The answer to these questions is given by modern brain research and cognitive science. Behavior of human persons depends on brain dynamics. Perceptions, emotions, thoughts, and consciousness correspond to neural patterns, self-organizing by neurochemical interactions. Neuropsychology analyzes intentions and preferences as neural states of interacting neural areas. But the brain does not work as a usual computer with formal programs and formal symbols. Our skills do not depend on formal knowledge and its symbolic representation in programs. Rational thoughts with symbolic representations (e.g., formulas in logic and programming languages) do not guarantee adaptive behavior. Adaptive behavior in sudden situations does not depend on logical inferences, but on bodily interactions with an external environment (e.g., looking, feeling, reacting). Therefore, we distinguish embodied skills and formal knowledge.

Cognitive science analyzes formal and embodied learning. Chess is an example of a formal game with complete representations, precisely defined states, board positions, and formal operations. Soccer is a nonformal game with skills depending on bodily interactions, without complete representations of situations and operations that are never exactly identical—as our life, only much more simple. But not only "low level" motor intelligence, but also "high level" cognition (e.g., categorization) emerge from complex bodily interaction with an environment by sensorymotor coordination without internal representation. An infant learns to categorize objects and to build up concepts by touching, grasping, manipulating, feeling, tasting, hearing, and looking at things and not by explicit representations. The categories are fuzzy and will be improved and changed during life.

Learning is made possible by consciousness as well as unconsciousness. Consciousness and unconsciousness are assumed to be realized by different neural systems of the brain. Consciousness is a cognitive state mainly generated by the associative cortex interacting with the primary sensory cortex areas. Their high 
synaptic plasticity and storage capacity enable explicit and declarative learning and problem solving. But their complex activities are energetically expensive. Unconsciousness is generated by the sensory and primary motoric cortex, pons, cerebellum, subcortical limbic, and motoric centers. It enables automatic, implicit, and procedural learning and memory, which is sometimes called tacit knowledge. The concept of tacit knowledge was introduced by the British philosopher and economist Michael Polanyi (Dierkes et al. 2001).

Further on, human life is dominated by emotions generated by the limbic system. The emotional memory stores all experiences and evaluates them by spontaneous bodily feeling of wellness, anger, fear, etc. Thus, emotions are embodied processes of the whole organism, which cannot be located to special areas of the brain. The bodily expressions of emotions are sometimes called somatic markers. Obviously, there are severe consequences for pragmatic education: If intentions are only dictated from outside without using emotional memory, the control of planning and acting is not motivated, spends immense energy, and sickens people. Therefore, somatic markers should be used to motivate people. For example, corporate identity of a company is supported by common feeling and experiences of groups. Managers should be sensible for the emotions of people and not only argue from a rational point of view. Embodied emotions support self-regulated control of long-term plans and intentions.

In general, the learning brain is determined by an interaction of two forces-on the one side, conscious cognition with rapid and explicit learning and on the other side, emotional conditioning with slow, implicit, and sustainable learning. The involved areas of the brain are well known in brain research and cognitive science. The embodied mind enables a complex variety of creative competences. Human beings are not specialized to distinguished skills like animals, well adapted to fixed ecological niches. There is a variety and distribution of more or less developed competences such as linguistic skills (e.g., journalists, writers), logical-mathematical capacities (e.g., mathematicians), musical gifts (e.g., composers), spatial imagination (e.g., architects), bodily kinesthetic skills (e.g., dancers), social skills (e.g., teachers), experimental-observational capacity (e.g., natural scientists, physicians), and technical skills (e.g., engineers). Their synergetic interaction provides new ideas, problem solving, and innovation. Human creativity is a result of the embodied mind.

The distinction of consciousness and unconsciousness leads to explicit and tacit skills and knowledge. Tacit knowledge means skills of bodily experience, simultaneous knowledge here and now, or analog knowledge of practice. Explicit knowledge comprises rational knowledge, sequential knowledge there and then, and digital knowledge of theory. There is a conversion process of knowledge and skills with four categories of socialization, externalization, combination, and internalization. Socialization means accumulation of tacit knowledge, extra- and intraorganizational collection of social information. Externalization is the transfer from tacit knowledge to explicit knowledge. People become aware of their know-how and skills. Therefore, managers should facilitate creative and essential dialogues, hypothetical thinking, and the use of metaphors. Combination includes the acquisition and integration of explicit knowledge with plans and computer 
documents, manuals, and databases. Internalization is the way from explicit to tacit knowledge. People transform their learned explicit knowledge into personal experience and bodily skills. These steps of conversion are sometimes called empathizing tacit knowledge during socialization, articulation of tacit knowledge during externalization, connecting of explicit knowledge during combination, and embodying explicit knowledge during internalization. On that background, we can distinguish four creative potentials in organizations and companies: (1) experimental knowledge assets with tacit knowledge shared through common experiences (e.g., skills and know-how of individuals, care, trust, energy, passion, and security), (2) conceptual knowledge assets with explicit knowledge articulated through images, symbols, and language (e.g., product concepts, design, brand equity), (3) systemic knowledge assets with systemized and packed explicit knowledge (e.g., documents, specifications, manuals, database, patents, and licenses), and (4) routine knowledge assets with tacit knowledge routinized and embedded in actions and practices (e.g., know-how in daily operations, organizational routines, and organizational culture) (Tomaschek 2006).

\section{Carl von Linde-Academy: key research and competence education}

Which educational consequences can be concluded from these insights of modern brain research, cognitive science, and organizational psychology and sociology? The Technical University of Munich (TUM) can be considered on the background of innovation dynamics and education. TUM has a great tradition since the nineteenth century and is today one of Germany's universities of scientific excellence. TUM unifies a variety of disciplines in faculties of mathematics, physics, chemistry, civil engineering and surveying, architecture, mechanical engineering, electrical engineering and information technology, informatics, life and environmental science, medicine, sports science, and economics. In the tradition of the École Polytechnique, TUM is considered an innovation enterprise with a distinguished combination of natural science, medicine, and life sciences. Further on, interdisciplinary platforms, research projects, and courses of study have been created across all faculties. According to American elite universities, TUM is surrounded in Munich by a ring of local centers of enterprise. Globally, strategic partnerships with other universities intensify exchange in teaching and research. The integration of industrial global players creates resources for international activities.

The Carl von Linde-Academy is an answer to the cross-over innovation dynamics and cultural challenge in the age of globalization. The foundations of innovation dynamics are a main topic of interdisciplinary research and philosophical reflection at the Carl von Linde-Academy (compare chapter 2). Its head is combined with a chair for philosophy of science. Innovation dynamics is only an example for the nonlinear dynamics of complex systems, which are analyzed interdisciplinarily in nature, technology, economy, and society. There have been several book publications, conferences, and research projects with the TUM Institute for 
Advanced Study, Academy of Europe (Academia Europaea/London), and several research foundations in these main fields of research interest.

But highly specialized knowledge is not sufficient. Interdisciplinary and intercultural thinking is the strategic condition, in order to decide and act with responsibility. We need a variety of skills generated by the embodied mind, which was explained in the last chapter. The foundation of the Carl von Linde-Academy was strongly supported by officials of state, economy, and society.

The objectives of foundation aim at opening minds for scientific cultures, promoting the transfer of knowledge and skills from other disciplines, and strengthening the sense of responsibility. The head of the Carl von Linde-Academy is the academic director assisted by a managing office with a manager and a manager assistant. The academic director is professor for philosophy of science with a stuff of coworkers. Every semester, the academic director and his team organize a program for the whole university with studies of philosophical, cultural, and social competence, a course for philosophy of engineering in the bachelor program of engineering, a master program for philosophy of science and technology, interdisciplinary courses for the TUM graduate school, and courses of teaching skills (PROLEHRE). The educational program is offered by ca. 70 lecturers, which is financially supported by the Linde Foundation of the Academy.

The mission of the Academy is "Find and support creative potentials of TUM". Competence means knowledge plus skills. The program of interdisciplinary and intercultural studies for students is anchored in the study and examination regulations. We promote an elected circle of specially gifted students by an additional master degree for philosophy of science and technology. Further on, the quality of teachings should be supported with continuous evaluation and development of all learning modules. Top issue is the human personality in the age of globalization. Personality needs motivation and creativity, responsibility, selforganization and self-performance, communication and cooperation, and qualities of leadership. Globalization comprises complexity of a global world, responsibility in a global world, worldwide interaction of economy, science, and politics, cultural communities and differences, risks and conflicts. Education in these two top issues enables cross-thinking and cross-acting with interdisciplinary thinking in complex systems (e.g., natural science, engineering, economics, humanities), deciding and acting in complex organizations (e.g., political, economic, scientific organizations), and evaluating in complex cultures (e.g., ethical values).

In more details, there are six educational modules: complex systems and globalization, communication and information, ethics and responsibility, cultural competence, values and change, and innovations and risks. The educational program with courses of these modules is supplemented by events of arts, self-management, and savoir vivre. Courses in the six modules lead to interdisciplinary qualifications with respect to the Bologna process: With three courses in the same module, a student gets a certification. Three certifications deliver a key qualification for the special disciplines in the faculties (e.g., mathematics, natural sciences, engineering, and medicine). Key qualifications supplement disciplinary studies. We distinguish basic skills of methodic competence and self-competence and orientation skills in economic, political, cultural, and ecological systems. Enabling skills of formal and 
operational knowledge are trained in the special studies of faculties and departments. Further on, educational forms must be chosen according to the embodied mind with workshops, series of lectures, blended learning units, summer schools, and tutorials.

Every semester, we offer a program with courses, workshops, and events. Typical titles of courses are, e.g., "Randomness, Risks, and Innovations", "Management of Complex Organizations", "Emotional Intelligence", "Communication, Information, and Media", "Cultural Competence". Workshops discuss issues of philosophy of science, economy, and psychology (e.g., "Embodied Mind", "Tacit Knowledge and Creative Skills", "Deciding with Bounded Rationality"). According to their embodied mind, human beings are bodily beings with emotions, imagination, and feeling. Thus, we also offer guided tours with memorials and media, mobility and technology in architecture, talks in the Pinakothek of Modern Arts, and, last but not least, courses of savoir vivre on culture of wine, dinner, and cooking. Every semester, there is a popular lecture to the broader audience of Munich, organized by the Carl von Linde-Academy. Titles of these lecture concern hot topics at the boundary of science, technology, economy, culture, and politics.

The mission of PROLEHRE means supporting the academic teaching at TUM to give students the best possible teaching. PROLEHRE is responsible for assuring and improving teaching quality, supporting teachers to develop and professionalize their individual teaching style, voluntary course- and coaching offers with statewide accepted certificates. Typical activities are training of lectures, individual coaching of lecturers, evaluation of teaching quality, developing and providing didactic advice, supporting innovative teaching pilot programs, consulting academic staff in teaching matters, and maintaining a dialogue on teaching culture. PROLEHRE offers courses on methodology of academic teaching, rhetoric and communication, media and e-learning, teaching and learning in a cross-cultural context, and groupworking techniques.

The new media play an immense role in global education. In knowledge society and knowledge-based economy, knowledge and skills of citizens are becoming increasingly important. Under this perspective, a new paradigm of personalized on-demand learning emerges, where anyone, anytime, anywhere delivery of education and training is adapted to specific requirements and preferences of each individual citizen within different e-learning and e-working settings. When organizations (e.g., firms, universities, research laboratories, suppliers, and customers) become allies in partnership, a new platform for learning is addedthe inter-organizational one. When organizations begin to adapt to larger networks, platforms for learning multiply. Virtual organizations are systems of networking partners who coordinate their activities through shared missions, visions, values, projects, and products.

Thus, in the age of globalization, the Carl von Linde-Academy is a center of interdisciplinary and intercultural research and education in the old European tradition of humanism from Athen's Academy to the École Polytechnique, embedded in the Technical University of Munich (TUM) as global player of research and innovation. 


\section{References}

Balke W-T, Mainzer K (2005) Knowledge representation and the embodied mind: towards a philosophy and technology of personalized informatics. In: Lecture notes of artificial intelligence 3782, professional knowledge management. Berlin, Springer, pp 586-597

Bekey GL (2005) Autonomous robots. From biological inspiration to implementation and control. MIT Press, Cambridge

CoTeSys (2006-2011) is funded by the German Research Council DFG as a research cluster of excellence within the "excellence initiative" from 2006-2011, see also www.dfg.de/en/research. funding/coordinated.programmes/excellence.initiative

Dierkes M, Berthoin Antal A, Child J, Nonaka I (2001) Handbook of organizational learning \& knowledge. Oxford University Press, Oxford

Feynman R (1959) The classic talk that Richard Feynman gave on December 29th 1959 at the annual meeting of the American Physical Society at the California Institute of Technology (Caltech) was first published in the February 1960 issue of Caltech's Engineering and Science, which owns the copyright. It has been made available on the web at http://www.zyvex.com/nanotech/feynman.html

Floreano D, Mondada F (1996) Evolution of homing navigation in a real mobile robot. IEEE Trans Syst Man Cybern B Cybern 26:396-407

Freeman WJ (2004) How and why brains create meaning from sensory information. Int J Bifurc Chaos 14:515-530

Mainzer K (2005) Symmetry and complexity. The spirit and beauty of nonlinear science. World Scientific Publisher, Singapore

Mainzer K (2007) Thinking in complexity. The computational dynamics of matter, mind, and mankind, 5 th edn. Springer, New York

Mainzer K (2008a) The emergence of mind and brain: an evolutionary, computational, and philosophical approach. In: Banerjee R, Chakrabarti BK (eds) Models of brain and mind, physical, computational and psychological approaches. Elsevier, Amsterdam, pp 115-132

Mainzer K (2008b) Komplexität. UTB-Profile, Munich

Mainzer K (ed) (2009) Complexity, European review, vol 17, no 2. Cambridge University Press, Cambridge, pp 219-452

Mainzer K (2010) Leben als Maschine Von der Systembiologie zur Künstlichen Intelligenz und Robotik. Mentis, Paderborn

Pfeifer R, Scheier C (2001) Understanding intelligence. MIT Press, Cambridge

Schumpeter JA (1939) Business cycles: a theoretical, historical and statistical analysis of the capitalist process. McGraw-Hill Book Company, New York

Thrun S, Burgard W, Fox D (2005) Probabilistic robotics. MIT Press, Cambridge

Tomaschek N (2006) Systemic coaching. A target-oriented approach to consulting. Carl-Auer Verlag, Heidelberg 